\title{
RELIABILITY OF DUNE EROSION ASSESSMENT ALONG CURVED COASTLINES
}

\author{
B.M. (Bas) Hoonhout ${ }^{1}$ and C. (Kees) den Heijer $^{2}$
}

\begin{abstract}
The dune assessment methods used to ensure the safety of the lower areas in The Netherlands are based on simple empirical relations that are, strictly speaking, only valid for infinitely long, uniform and straight coasts. The wide application of these relations is mainly justified due to intentional overestimation of the expected dune erosion. In context of climate change and expected sea level rise, it is worthwhile to investigate the needs for this overestimation before any physical measures are taken. This paper describes a research to the influence on the dune erosion process of two longshore phenomena that are neglected in these relations so far: coastal curvatures and oblique wave attack. It is shown that the normative retreat distance can increase over $100 \%$ for curvatures relevant for The Netherlands. Furthermore, it is shown that the sensitivity of dune erosion models changes when working with curved coastlines. It is also shown that the importance of several model parameters is influenced by coastal curvatures and special attention should be paid to the correlations between storm surge levels and wave parameters.
\end{abstract}

Keywords: dune erosion; curved coastlines; reliability; assessment

\section{INTRODUCTION}

Over fifty percent of The Netherlands is located below mean sea level (Figure 1). In addition, these lower areas are the most densely populated and economically valuable areas in the country. A reliable water defense system is therefore of vital importance for The Netherlands.

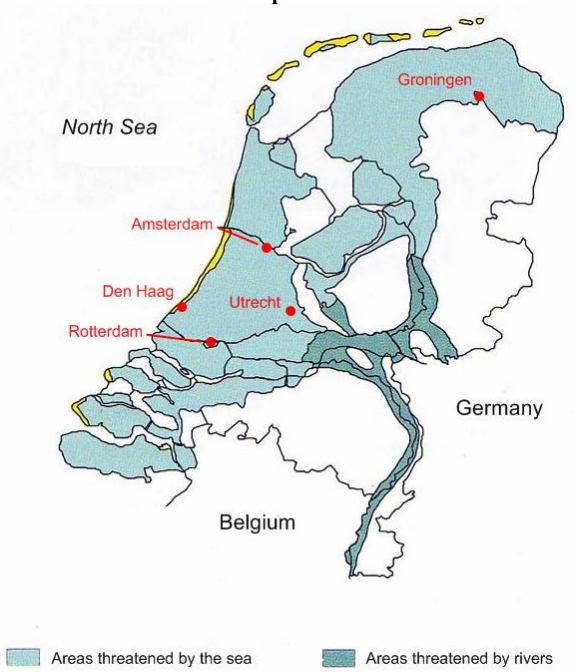

Figure 1 Areas in the Netherlands threatened by the sea and rivers.

Since the second half of the twentieth century an extensive collection of legal regulations ensure the safety of the lower areas in the Netherlands (VTV2006). These regulations enforce, among others, a five-yearly assessment of all water defenses according to specified assessment methods. A major part of the sea defense consists of dunes. Therefore an appropriate assessment method for dunes is essential.

The current assessment methods for dunes are based on simple empirical relations (Vellinga, 1986, WL | Delft Hydraulics, 2006). Although continuous effort is being made to improve the understanding of the dune erosion process and the accuracy of the assessment methods, strictly speaking these methods are only valid for infinitely long, uniform and straight coasts. Obviously, the Dutch coast with its curvatures, islands and estuaries does not meet these prerequisites (Figure 1).

The wide application of the currently used relations is mainly justified due to intentional overestimation of the expected dune erosion (Steetzel, 1992b). Because of expected changes in climate and corresponding sea level rise, it is presumable that at a certain moment the Dutch dune system ceases to meet the legal regulations. Before the dunes are reinforced, it is worthwhile to reduce the

\footnotetext{
${ }^{1}$ Deltares, Unit Hydraulic Engineering, Rotterdamseweg 185, 2629HD Delft, Netherlands

${ }^{2}$ Delft University of Technology, Hydraulic Engineering, Stevinweg 1, 2628CN Delft, Netherlands
} 
need for overestimation by improving the understanding about the dune erosion process and thereby the actual safety level of the dunes. This will lead to a more reliable and effective coastal management.

To be able to cope with the large number of uncertainties involved in dune erosion computations, a renewed and more accurate probabilistic computational method is currently under development in The Netherlands (Walstra et al., 2008). One of the subjects that is not yet extensively studied in this context is the influence of the alongshore dimension, which includes the influence of coastal curvatures and oblique wave attack. The research described in this paper focuses on these two phenomena.

\section{Problem description and objectives}

It is known that the influence of coastal curvatures on the amount of dune erosion is considerable. Some research on this subject has resulted in the current Dutch legal regulations concerning curved coastlines (Dillingh, 1984). The research was based on a limited data analysis (Vellinga, 1983), which resulted in a cautious guideline. It is therefore expected that the current regulations underestimate the influence of coastal curvatures on the amount of dune erosion.

In context of the formulation of a renewed probabilistic computational method for safety assessment of Dutch dunes, little is known about the relation between curved coastlines and probabilistic models. It is questioned whether longshore phenomena in general and curved coastlines in particular should become part of the newly formulated probabilistic computational method.

Oblique wave attack is neglected so far in computational methods since it reduces the expected amount of dune erosion. Neglecting oblique wave attack thus results in a conservative estimate. However, a close relation exists to the physics involved in dune erosion along curved coastlines. The interaction between both phenomena and the process of dune erosion might therefore be important for a full understanding of this matter.

The overall objective of this research is to quantify the relevance of the incorporation of coastal curvatures and oblique wave attack in any renewed and more accurate probabilistic computational method. The change in dune erosion volumes, and thus in probability of failure, due to either one or both phenomena is examined. Furthermore, it is investigated which aspects of the dune erosion process are particularly of interest for curved coastlines. This includes the physical and probabilistic simulation of this process.

\section{HYPOTHESES}

Using a numerical dune erosion model, several hypotheses are tested involving coastal curvatures and oblique wave attack. These hypotheses are described below. The hypotheses can be subdivided in roughly three groups. The next three subsections correspond to these groups.

\section{Probability of failure}

The probability of dune failure is the ultimate parameter of interest. Based on this parameter the safety of the Dutch dune system can be assessed and coastal management policies can be defined. The probability of dune failure is expressed as a frequency of exceedance of a certain critical retreat distance. The hypotheses formulated concerning just the probability of dune failure are:

1. The probability of dune failure increases with increasing coastal curvature in case of convex coastlines.

2. The probability of dune failure decreases with increasing incident wave angle.

3. The effect of the coastal curvature on the probability of dune failure diminishes for increasing incident wave angles.

The effect of increased dune erosion along curved coastlines with respect to straight coastlines is considered to be due to a more effective transport of suspended sediment from the observed coastal ray. A sediment transport gradient not only exists in cross-shore direction, but also in longshore direction. The effectiveness of this longshore transport gradient in terms of fractions of transport of suspended sediment might actually increase with increasing incident wave angles. This is due to the non-linear relationship between erosion 
volume and incident wave angle. However, the rapid decrease of the amount of suspended sediment due to an increasing incident wave angle can compensate this. It is expected that the amount of suspended sediment, with respect to the reference case with perpendicular wave attack, is ultimately not enough to reach the erosion volumes corresponding to this reference case.

\section{Legal regulations}

In this section several hypotheses regarding the current legal regulations concerning the Dutch coast are formulated. These hypotheses are:

4. The normalized effect of the coastal curvature will be larger for hydraulic conditions where waves dominate in favor of the storm surge level.

As stated before, it is expected that a coastal curvature increases the effectiveness of wave action with respect to dune erosion. This implies that locations with hydraulic conditions that impose a lot of wave action rather than a high storm surge level, can expect a larger increase of erosion volumes in case a coastal curvature is introduced than locations that suffer from high storm surge levels, but moderate wave action.

5. Current legal regulations underestimate the influence of coastal curvatures and the incident wave angle.

The elaboration of the current legal regulations concerning coastal curvatures did not result in a universal computational rule, but was "for this moment only a basis for dune erosion computations for curved coastlines" (Dillingh, 1984). The computational rule was upon introduction already expected to underestimate the influence of the coastal curvature. It was accepted because it was nevertheless an improvement in the applicability of the legal regulations. Other research showed later that the underestimation was probably considerable (Steetzel, 1990).

6. Current legal regulations overestimate the probability of dune failure in general and also in case of curved coastlines.

The current legal regulations prescribe the use of the DUROS+ model (Vellinga, 1986). This model overestimates the actual erosion volumes considerably (Steetzel, 1992b). It is expected that the underestimation of the influence of the coastal curvature only decreases the overestimation of the erosion volumes, but does not exceed it.

\section{Relative importance}

The relative importance of a model parameter is a measure for the sensitivity of some kind of result for that specific parameter. This result can be a model result like erosion volume or retreat distance, but also a probability of failure. The concept of sensitivity in the traditional sense appeared to be too narrow in context of probabilistic models; therefore the concept of relative importance is introduced. Since this concept is not trivial, a discussion about this subject can be found in Hoonhout (2009).

The most important notion about relative importance is that it consists of two parts. The first part only relates to the deterministic and physical sensitivity of the model parameters to the model result, which is an erosion volume or a retreat distance. The contributions are directly related to the model itself and do not incorporate any probabilistic correlations. This is in agreement with the traditional concept of sensitivity and is from now on referred to as the deterministic relative importance. The second part relates to the influence of the model parameters on the probability of a certain erosion volume or retreat distance to occur. This involves both physics and probabilistics and is from now on referred to as the probabilistic relative importance. In order to be able to compare both concepts, an intermediate and theoretical concept is introduced that incorporates a limited number of probabilistic properties in the deterministic concept of relative importance. This concept is referred to as semiprobabilistic relative importance.

The hypotheses formulated concerning the relative importance of the model parameters are: 
7. The deterministic and probabilistic relative importance of the storm surge level decrease with increasing coastal curvature in case of convex coastlines.

As stated before, suspended sediment is not only transported in cross-shore direction, but also in longshore direction in case of curved coastlines. A larger fraction of the suspended sediment is actually transported from the observed coastal ray. Sediment comes into suspension by wave action. This implies that the wave action becomes more effective in the transport of sediment and thus more important in the erosion process and ultimately in the probability of dune failure. Of course sediment characteristics influence the amounts of suspended sediment as well and thus it is expected that the importance of the sediment parameters increase as well. A certain storm surge level is in fact a prerequisite to obtain a certain amount of erosion, but the wave action actually erodes the dune. Therefore, it is expected that the increase in effectiveness of the wave action will lead to a decrease in the importance of the storm surge level.

8. The deterministic and probabilistic relative importance of the sediment and wave parameters increase with increasing coastal curvature in case of convex coastlines.

9. The deterministic and probabilistic relative importance of all model parameters are not influenced by the incident wave angle.

In contrast with the introduction of a coastal curvature, whereby a longshore transport gradient is introduced, the introduction of just an incident wave angle does not change the dune erosion process. The process only becomes less effective. This decrease of effectiveness is not expected to influence the relative importance.

\section{MODEL SET-UP}

The hypotheses summarized in the previous section are tested using a numerical dune erosion model in conjunction with a probabilistic model. Both models and the used set-up are explained in this section.

\section{Dune erosion model}

Three dune erosion models are considered for the use during this research: DUROS+ (Vellinga, 1986, WL | Delft Hydraulics, 2006), DurosTA (Steetzel, 1993) and XBeach (Roelvink et al., 2006). Although XBeach is the only true 2DH model from those three, little experience is gained using the $2 \mathrm{DH}$ features of this model as for now. A theoretical research, expecting near-to-exact results did not seem to be feasible at this moment. The original DUROS model does not include longshore phenomena. To include the influence of coastal curvatures, the model is extended using the formulation of Dillingh (1984). However, the capabilities of DUROS+ to simulate longshore phenomena are still very limited. Furthermore, a considerable part of this research in fact involves the verification of these capabilities since this model is prescribed in the current Dutch legal regulations concerning the safety assessment of dunes. In this paper, when referred to DUROS+, the model including curvature extension is meant.

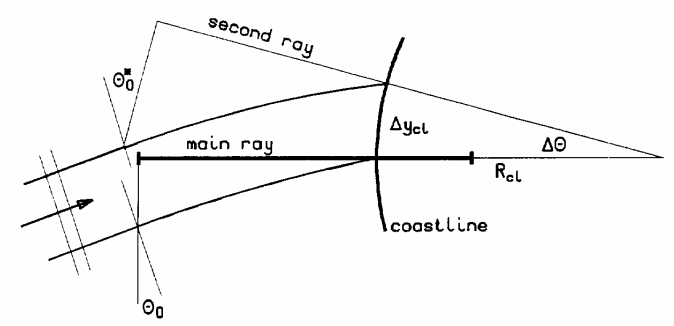

Figure 2 Principle of DurosTa's double-ray approach (Steetzel, 1993).

The DurosTA model is chosen for the use during this research. DurosTA is a semi-2D dune erosion model that uses a secondary cross-shore ray to approximate longshore velocities and transports due to longshore gradients caused by tides or coastal curvatures (Figure 2). The model is 
initially developed for research to longshore phenomena. See Steetzel (1993) and Hoonhout (2009) for more information concerning these approximations.

The model set-up of the dune erosion model consists of a dune profile and hydraulic conditions and during this research also a coastal curvature. The dune profile is known to be an important parameter when calculating dune erosion volumes. Since this is not the parameter of interest during this study, it is kept constant. A schematized reference profile that is considered representative for the Dutch coast is chosen (Figure 3).

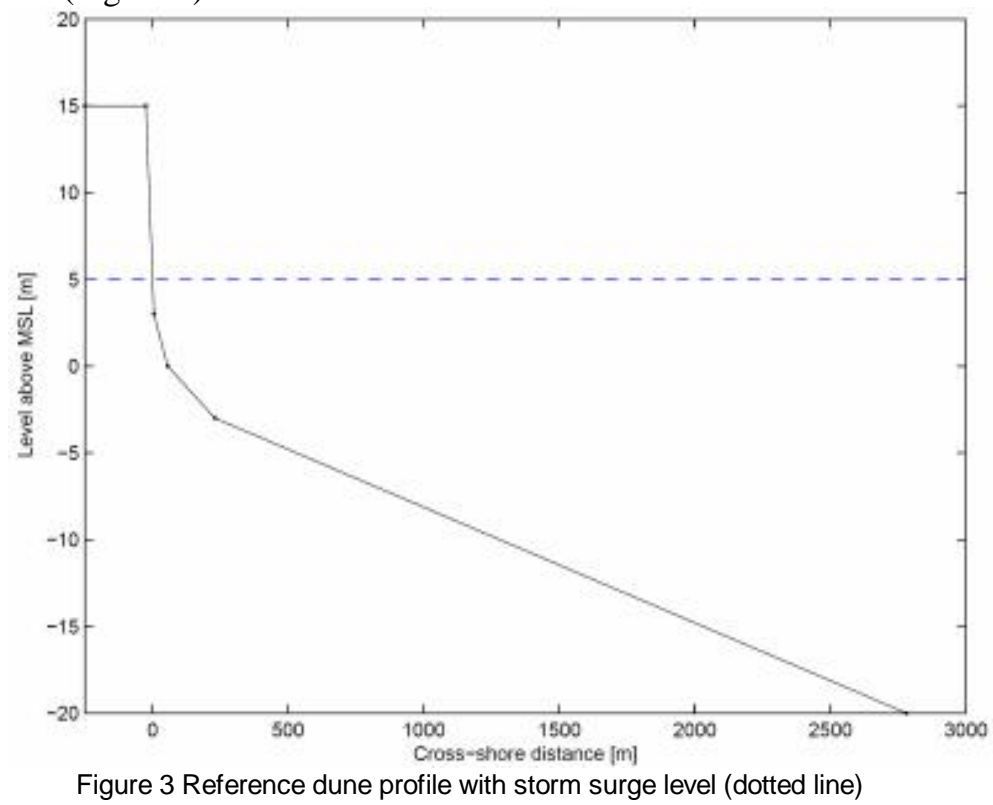

The hydraulic conditions are provided by the probabilistic model discussed in the next section. The coastal curvatures are expressed in coastal curvature radii and systematically varied using the following series: 1000, 1500, 2000, 2500, 3000, 3500, 4000, 4500, 5000, 6000, 7000, 8000, 9000, $10000,15000,20000$ and $\infty$ meters. In this series the 1000 meters value is chosen to limit the approximation errors made by the model and the 10000 to 20000 meters boundaries are chosen since in current Dutch legal regulations curvature radii larger than 9000 meters are considered to be straight. A coastal curvature of $\infty$ meters should be interpreted as being straight.

Sensitivity

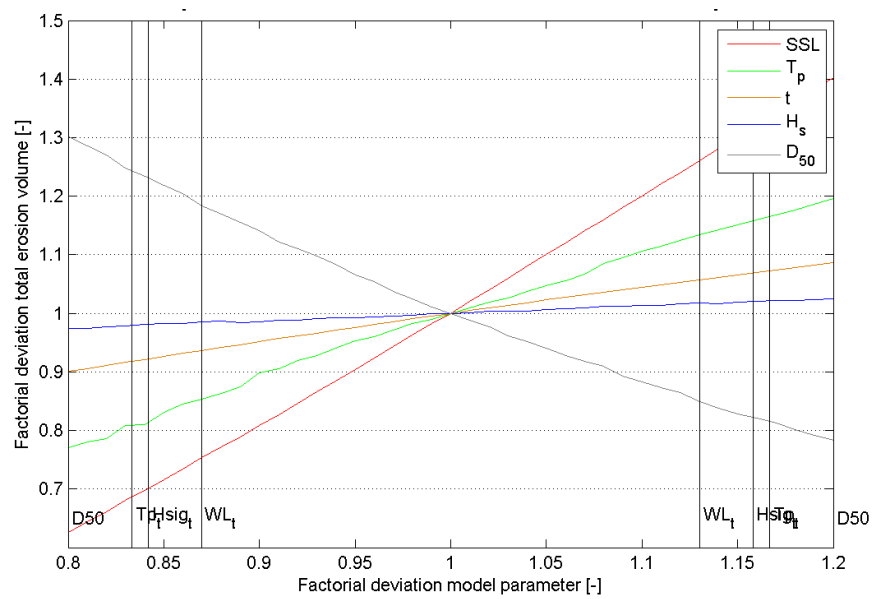

Figure 4 Sensitivity of total erosion volume calculated by DurosTA for different model parameters. Vertical lines indicate the variability of the model parameters.

As explained in the previous section it is expected that coastal curvatures influence the traditional sensitivity or deterministic relative importance of the dune erosion model. It is expected that the model gains sensitivity for the wave and sediment parameters. A traditional sensitivity analysis based 
on several reference cases with varying coastal curvatures is conducted to test this hypothesis. Figure 4 gives an example of such sensitivity analysis for the case with a straight coastline and coast normal wave attack.

If the sensitivity analyses for all reference cases are aligned and the deviations of the calculated erosion volumes due to a $10 \%$ deviation of each model parameter is plotted against the coastal curvature used in each reference case, Figure 5 is obtained. It can be seen that the sensitivity of the dune erosion model for especially the sediment diameter increases considerably with increasing coastal curvature or decreasing coastal curvature radius.

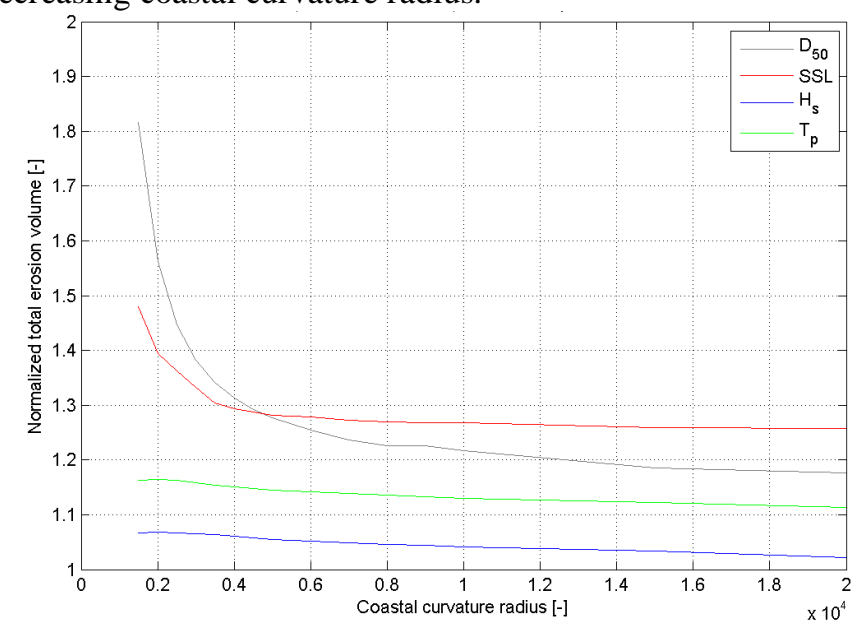

Figure 5 Sensitivity of total erosion volume calculated by DurosTA for model parameters depending on coastal curvature for a fixed change of $10 \%$ of the model parameters.

\section{Comparison}

Using the true 2DH XBeach dune erosion model for the entire research was not feasible. A basic comparison of the calculated longshore transports depending on the coastal curvatures is nevertheless possible. Due to the more advanced physics used in XBeach, it is expected that the XBeach results in the end will be more reliable. Calculated transports for a few simple cases should therefore not deviate too much between both models in order to entrust the results obtained using the DurosTA model.

The DurosTA model implicitly schematizes any coastal curvature as a 100 meters stretch of a perfectly circular coastline with a certain radius. To equate this situation in the XBeach model a 3D bathymetry consisting of several circular coastal stretches is used as presented in Figure 6. Furthermore, the model settings used are largely adopted from (Van Thiel de Vries, 2009).

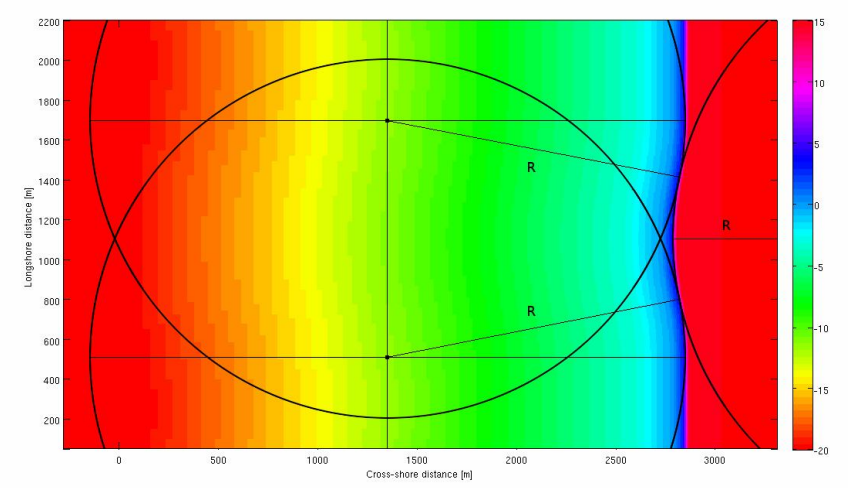

Figure 6 Composition of circular and straight coastal stretches used as bathymetry in XBeach simulations.

In order to be able to compare the results from both models as good as possible, the calculated longshore transport gradients are compared rather than the calculated erosion volumes. Therefore the models are run without the morphology being updated during the simulated storm event. This way the coastal curvature as well as the dune profile remains constant during the storm surge. Since the influence of the coastal curvature is investigated rather than the absolute longshore transport 
gradients, the results are normalized to a reference case. The most obvious reference case is the one containing a straight coast and coast normal wave attack. The longshore transport gradients, however, are then zero. This poses problems when normalizing the results. Therefore the results for a 10,000 meter radius and coast normal wave attack is used as reference case for normalization.

The comparison has been made for several representative combinations of coastal curvatures and incident wave angles using again the schematized dune profile. The coastal curvature radii used are $1500,2500,5000,10000,20000$ and $\infty$ meters. The incident wave angles used are 0,10 and 20 degrees with respect to the coast normal. The results for both models with coast normal wave attack are shown in Figure 7.

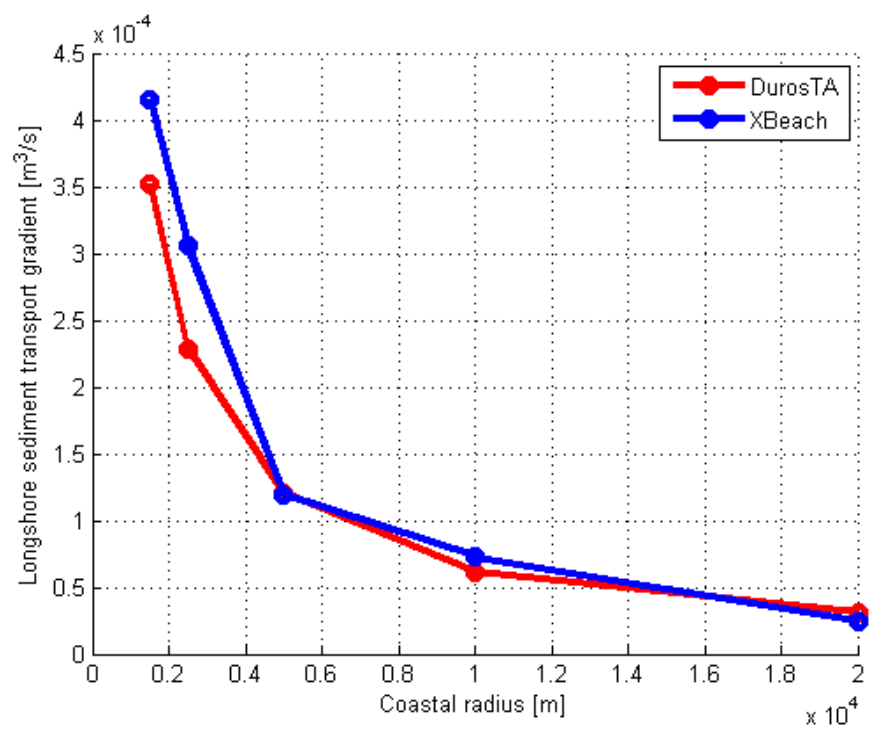

Figure 7 Comparison of longshore sediment transport gradients and cross-shore transports calculated using XBeach and DurosTA for different coastal curvature radii.

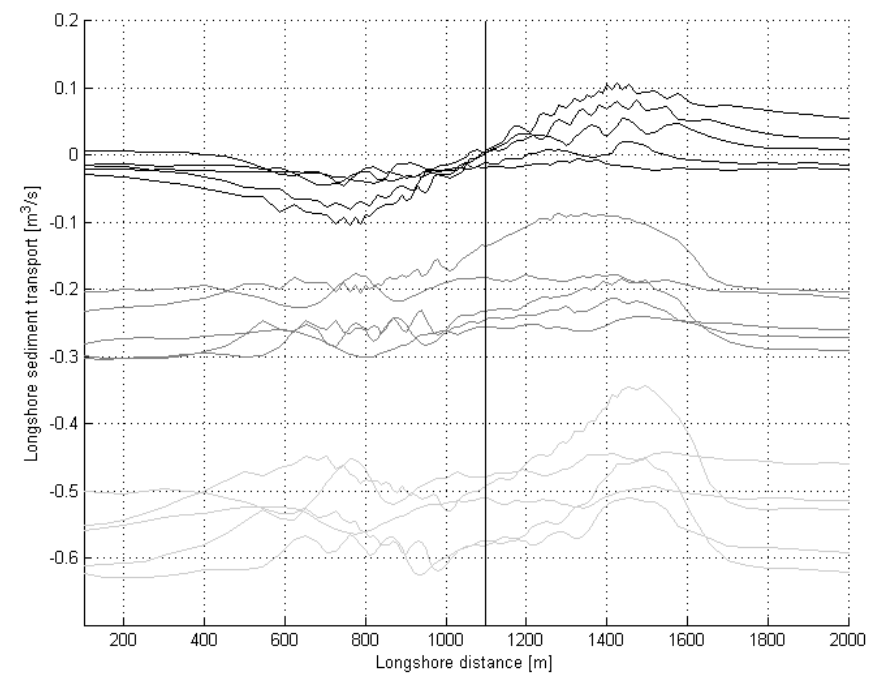

Figure 8 Longshore variations of longshore sediment transports calculated by XBeach for different combinations of incident wave angles and coastal curvatures.

It can be seen that the influence of coastal curvatures according to DurosTA and XBeach is fairly similar. For situations with oblique wave attack, the results deviate more. The deviation could be due to shading of the waves by the coastal bulb (Figure 6), which is taken into account in the 2DH XBeach model, but not in the DurosTA model. This explanation is supported by the longshore variation of the longshore sediment transports calculated by XBeach (Figure 8). Opposed to the situation with coast normal wave attack, the variation of the longshore sediment transports is not symmetrical for situations with an incident wave angle that is not coast normal. The steepness of these curves at the 
center of the bulb (vertical black line) is a measure for the longshore sediment transport gradients as showed in Figure 7. This steepness is obviously influenced by the asymmetry of the curves. Additional computations should clarify this behavior.

\section{Probabilistic model}

For all probabilistic calculations made during this research, a Monte Carlo (Fishman, 1996) routine is used. The routine involves a 1,000 independent draws from given probability distributions for each calculation.

Two sets of probability distributions are used during this research. The sets are representative for the locations Hoek van Holland and Den Helder located in the south and north of the Holland coast respectively. These sets are chosen because of their difference in nature. At the location Hoek van Holland the storm surge level is relatively high, while the wave heights are relatively moderate. At the location Den Helder the storm surge level is relatively moderate, but the wave heights are relatively high. Since it is expected that the wave and sediment parameters gain importance with increasing coastal curvature, this difference in wave climate might be of interest. The sets of probability distributions contain distributions for the storm surge level, wave height, wave period, sediment diameter and incident wave angle. Both sets of probability distributions can be found in WL | Delft Hydraulics (2007) and Hoonhout (2009).

In the sets of probability distributions the storm surge level and wave parameters are correlated. The correlation is introduced because their common cause is wind. Therefore the average of the wave height is based on the realization of the storm surge level. Similar, the average wave period is based on the realization of the wave height.

As stated before, it is expected that coastal curvatures influence the importance of model parameters. In other words, it is expected that coastal curvatures influence the contribution of different model parameters to the model result. It is shown in the previous section that this is indeed the case from a deterministic, model related point of view. To investigate similar effects in a probabilistic manner, the location of the design point is observed for the different model runs.

The design point is the point in the solution space that indicates the most probable situation where failure just occurs. The location is a measure of the influence of the different probabilistic parameters involved in the model result. The design point results directly from level II probabilistic methods like FORM. Level III methods, like the Monte Carlo method used, do not return the design point. Also, the definition of failure is unclear when dealing with schematized dune profiles since a real breakthrough of the dunes is not possible.

To be able to use the design point as importance indicator the location of the design point is approximated based on the Monte Carlo result sets. The methods used are described in Meeuws (1997). Failure is defined as exceeding the retreat distance with a 1/4,000 years occurrence, which is for Hoek van Holland conditions roughly 30 meters.

\section{RESULTS}

The results from the tests performed and described in the previous section are presented below. In line with the presented hypotheses the results are subdivided in three subsections. First the probabilities of failure depending on the coastal curvature and the incident wave angle resulting from the series of model runs are presented. Second, a comparison with current regulation is presented. The third subsection presents the influence of the coastal curvature and the incident wave angle on the relative importance of the model parameters. This section concludes with an analysis of the accuracy of the results obtained.

\section{Probability of failure}

The probability of failure is presented for the two types of hydraulic conditions, corresponding to the locations Hoek van Holland and Den Helder, separately. The normative return period of those locations is 10,000 years. However, the normative return period applicable to the locations with the largest curvatures in The Netherlands is 4,000 years. The results are therefore presented as a retreat distance corresponding to both return periods separately.

Since the relative influence of the coastal curvature on the probability of failure is the main interest of this research, rather than the actual probability of failure, the resulting retreat distances are normalized to a reference situation. This reference situation is defined as the retreat distance obtained with coast normal wave attack along a straight coast for a certain set of hydraulic conditions and a 
certain return period. With two sets of hydraulic conditions and two return periods, this definition results in four reference retreat distances that are all set to unity.

Hoek van Holland

For the location Hoek van Holland the normalized results are presented in Figure 9. It can be seen that the retreat distance and thus the probability of failure, increases with increasing coastal curvature (i.e. decreasing coastal curvature radius) while it decreases with increasing incident wave angle. Furthermore the increase of the retreat distance due to a coastal curvature can be compensated by a sufficiently large incident wave angle. The influence for the strongest curvatures in The Netherlands (> $24 \%$ km or a radius $<2400 \mathrm{~m}$ ) used in current regulations exceeds $100 \%$. However, the more moderate curved coasts show a significant influence as well.

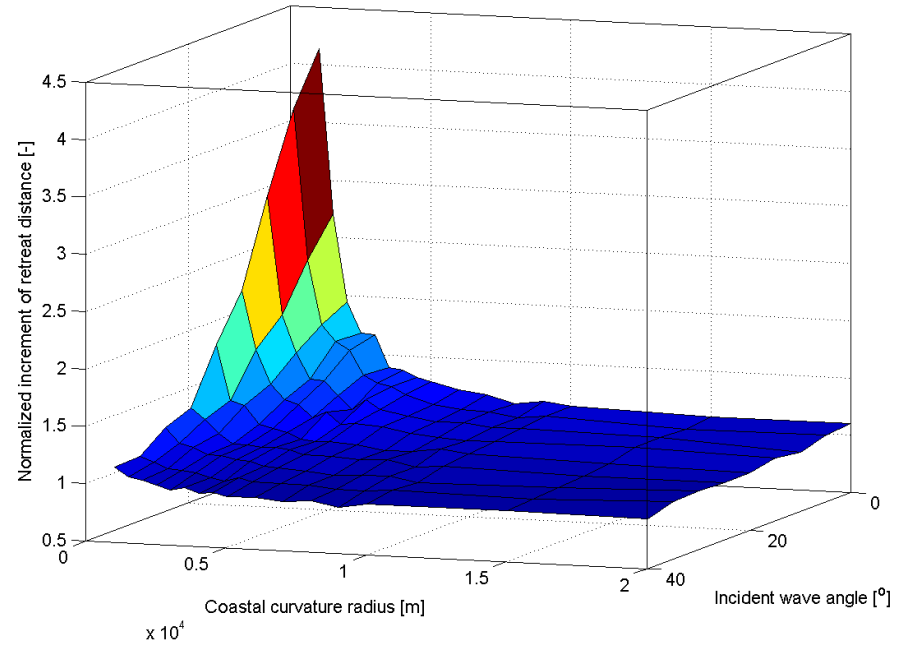

Figure 9 Normalized retreat distance with a return period of 10,000 years for Hoek van Holland conditions depending on the coastal curvature and incident wave angle.

For certain specific curved coastal stretches in The Netherlands related to the Hoek van Holland conditions, the increase of the retreat distance due to the coastal curvature with respect to the reference situation is given in Table 1. The normative return period for these locations is 4,000 years.

\begin{tabular}{|c|c|c|}
\hline Location & Curvature & Increase \\
\hline Oostkapelle - Vrouwenpolder & 4000 & $29 \%$ \\
\hline Schouwen & 3600 & $31 \%$ \\
\hline Ouddorp & 1800 & $88 \%$ \\
\hline
\end{tabular}

\section{Den Helder}

For the location Den Helder similar normalized results to for Hoek van Holland are obtained. The dependence of the retreat distance on the coastal curvature and the incident wave angle shows similar trends like at Hoek van Holland.

For certain specific curved coastal stretches in The Netherlands related to the Den Helder conditions, the increase of the retreat distance due to the coastal curvature with respect to the reference situation is given in Table 2.

\begin{tabular}{|c|c|c|}
\hline \multicolumn{3}{|c|}{$\begin{array}{l}\text { Table } 2 \text { Increase of retreat distance due to coastal } \\
\text { curvature with respect to reference situation at reference } \\
\text { locations. Based on a return period of } 4,000 \text { years. }\end{array}$} \\
\hline Loca & Curvature & Increase \\
\hline Den Hoorn & 9200 & $15 \%$ \\
\hline
\end{tabular}

Depending on the observed return period the retreat distances for Den Helder are on average $4 \%$ 7\% larger than for Hoek van Holland. Although the average maximum storm surge level in Den Helder is lower, the higher and longer waves apparently compensate the low storm surge level in terms of resulting retreat distance. Furthermore, the difference increases with increasing coastal 
curvature (Figure 10) due to the increased efficiency of the transport of sediments suspended by wave action, which is more severe in Den Helder.

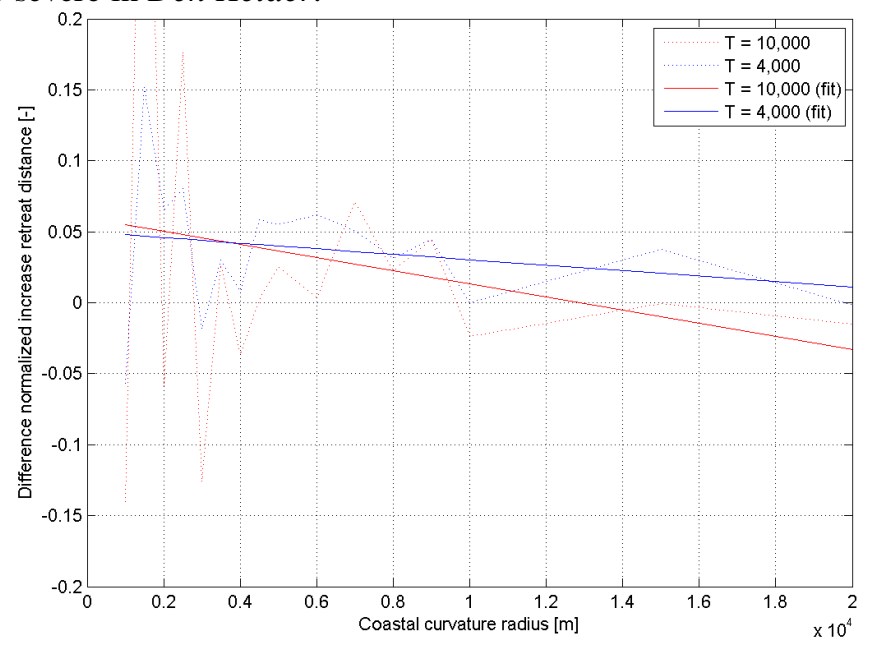

Figure 10 Difference in normalized retreat distance between calculations using the conditions representative for the locations Hoek van Holland and Den Helder depending on the coastal curvature.

\section{Legal regulations}

Current regulations prescribe the use of the dune erosion model DUROS+ (Vellinga, 1986; WL | Delft Hydraulics, 2006). DUROS+ is equipped with a simple module that incorporates the influence of coastal curvatures. DUROS+ can not cope with incident wave angles. Comparisons between the DUROS+ and DurosTA results are therefore with respect to the coastal curvatures only. Also the range of curvatures is limited for DUROS+, therefore only curvature radii larger than 2,000 meters are taken into account.

Since both models return considerably different retreat distances for the reference cases, both result sets are normalized to the reference result corresponding to the model used. A smaller increase due to a certain coastal curvature therefore does not necessarily mean that the resulting retreat distance is smaller. For the reference case and all other results, the frequency of exceedance is kept equal for both models. Another option was to keep the retreat distance equal. It was expected that the increase of, for example, a 1/4,000 year retreat distance with one meter is more likely to occur than of a 1/10,000 year retreat distance independent of the model used. Even if both retreat distances are equal when used with different models. The frequency of exceedance is therefore expected to be a better indicator for calibration. Preliminary calculations show this to be true.

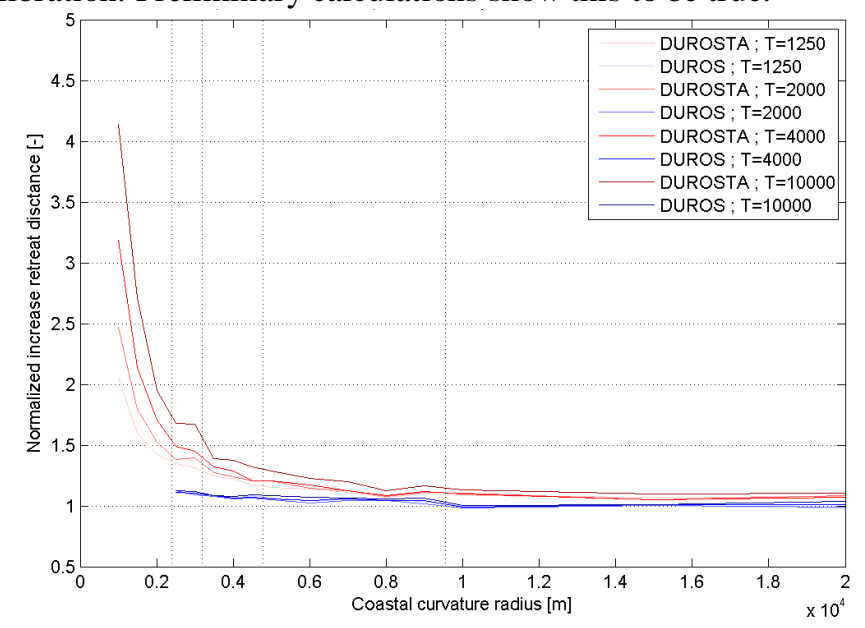

Figure 11 Comparison between DUROS+ and DurosTA normalized retreat distances for Hoek van Holland conditions and different return periods.

Figure 11 shows the comparison between the two models in terms of retreat distance depending on the coastal curvature. Figure 12 shows the difference between the DurosTA results and the 
DUROS+ results. It can be seen that the underestimation of the influence of the coastal curvature by current regulations is considerable. However, the DUROS+ model tends to overestimate the retreat distances in general. Therefore, the DUROS+ result is only for extremely curved coasts possibly not a conservative estimate. Furthermore, the difference increases with increasing coastal curvature as well as increasing return period.

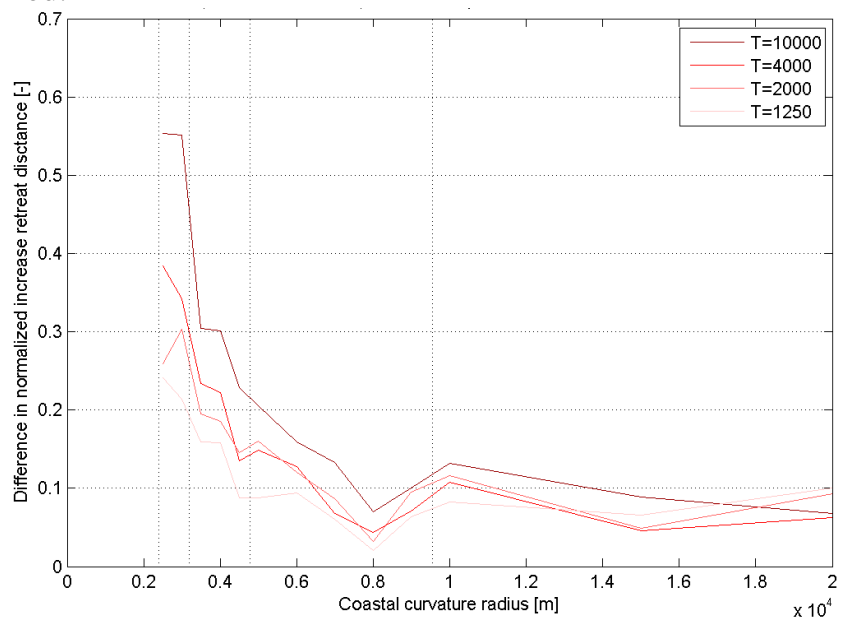

Figure 12 Difference between DUROS+ and DurosTA normalized retreat distances for Hoek van Holland conditions and different return periods.

\section{Relative importance}

In the previous sections it was shown that the sensitivity or deterministic relative importance of the sediment diameter increases considerably with increasing coastal curvatures. This analysis did not include any probabilistics. As explained in the previous sections as well, the design point can be used to include probabilistics in the analysis of relative importance resulting in the probabilistic relative importance.

Figure 13 shows the semi-probabilistic concept of relative importance, which is the increase of importance of the sediment diameter with respect to the other model parameters taking into account model physics and characteristic probabilistic values such as the average and standard deviation. The sum of all importances of all model parameters is in this case normalized and thus equal to unity. As can be seen from this figure the increase in importance of the sediment diameter is even more pronounced.

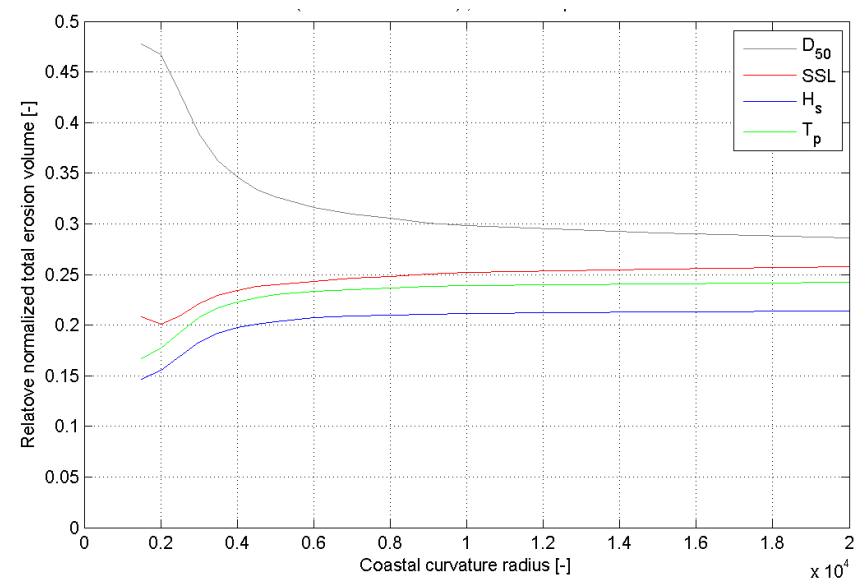

Figure 13 Importance of DurosTA model parameters for calculation of total erosion volume depending on coastal curvature.

The probabilistic concept of relative importance is expressed by a parameter that contains both the model physics as well as the full probabilistics involved. It is expressed in $\alpha^{2}$-values resulting from the formulation of the design point. The sum of all $\alpha^{2}$-values is unity. Since full probabilistics are involved, also the correlation between the maximum storm surge level and the wave parameters is 
reflected in the $\alpha^{2}$-values. Figure 14 shows the difference in $\alpha^{2}$-values depending on the coastal curvature with respect to the situation with a straight coast.

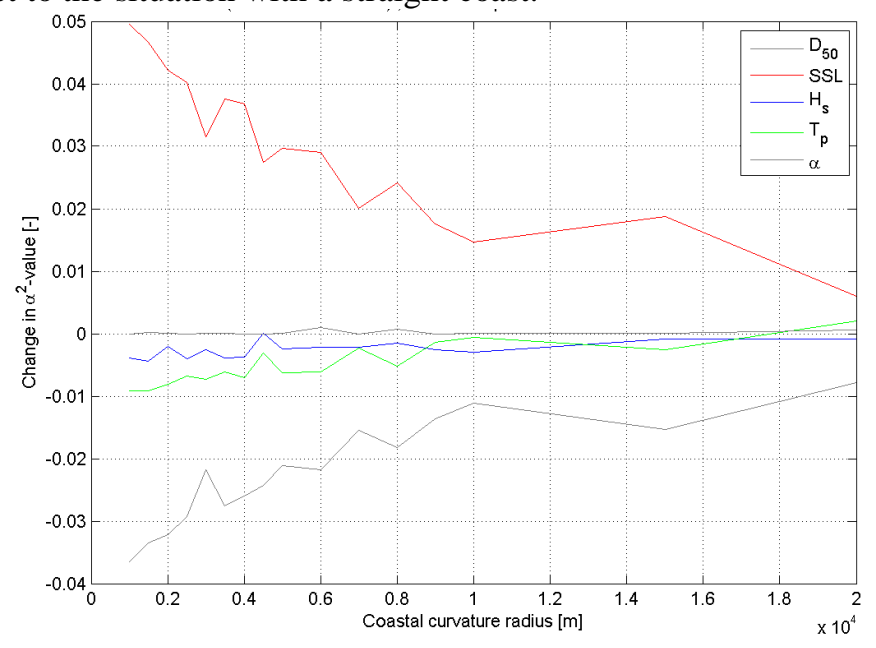

Figure 14 Change in $\alpha^{2}$-values depending on coastal curvature for Hoek van Holland conditions.

The trends of the $\alpha^{2}$-values appear to be opposite of the trend shown by the deterministic and semi-probabilistic relative importance. The storm surge level gains even more importance with respect to straight coasts, while the wave and sediment parameters loose importance. The redistribution of the importances with respect to the deterministic and semi-probabilistic relative importance can only be explained by the incorporation of the correlation between storm surge level and wave parameters. The storm surge level and wave parameters loose (semi-probabilistic) importance with increasing coastal curvature relative to the sediment diameter. However, the wave growth is limited by the storm surge level. The importance of the storm surge level and wave parameters are therefore bundled and the storm surge level indirectly gains importance from the wave parameters. Because the sum of all $\alpha^{2}$ values is equal to unity, the trends of all importances depending on the coastal curvature change. The difference between Figure 13 and Figure 14 actually reflect the increase of importance of the correlations between storm surge level and wave parameters.

Both the deterministic and the probabilistic relative importance are not significantly influenced by the incident wave angle, as expected. For moderate incident wave angles the process of dune erosion does not change, but becomes less effective with increasing incident wave angle. For very large incident wave angles some slight changes in process seem to occur, since the importance of the storm surge level slightly decreases. This decrease is not in favor of another parameter in particular and could be due to model limitations.

\section{Accuracy}

As determined in Steetzel (1992a) DurosTA underestimates the erosion volumes on average with $13 \%$ with a standard deviation of $18 \%$ with respect to measurements. Steetzel (1992a) states that DUROS overestimates the erosion volumes on average with $26 \%$ with a standard deviation of $28 \%$. Since no single erosion volumes are compared during this research, the inaccuracy of the models used is less severe than these numbers suggest. The average error is of minor importance because only relative changes depending on coastal curvatures or incident wave angle are observed. Furthermore the spread in the results is expected to be averaged out to some extend, since each retreat distance presented is determined based on a large number of simulations. The extend to which this expectation is reasonable, depends on the bias between the simulations. The use of the same probabilistics and dune profile for all simulations introduces a bias of which the magnitude can not easily be determined.

Furthermore, the Monte Carlo method used for this research is an approximating method that approaches the exact result with an increasing number of simulations and thus introduces an error as well. For this research, calculations with a 1,000 simulations are used, which resulted in a standard deviation in the retreat distance with a return period of 10,000 years of $\sigma=0.56 \mathrm{~m}$ for an average of $\mu$ $=32.39 \mathrm{~m}$, which is less than $2 \%$.

The accuracy of the determination of the probability of failure is indicated by the convergence diagram in Figure 15. For an increasing number of simulations per calculation the difference between 
successive calculations reduces, which is an indication of a reducing uncertainty. From the convergence diagram it can be concluded that the probabilities of failure are determined with an accuracy of $10^{-5}$.

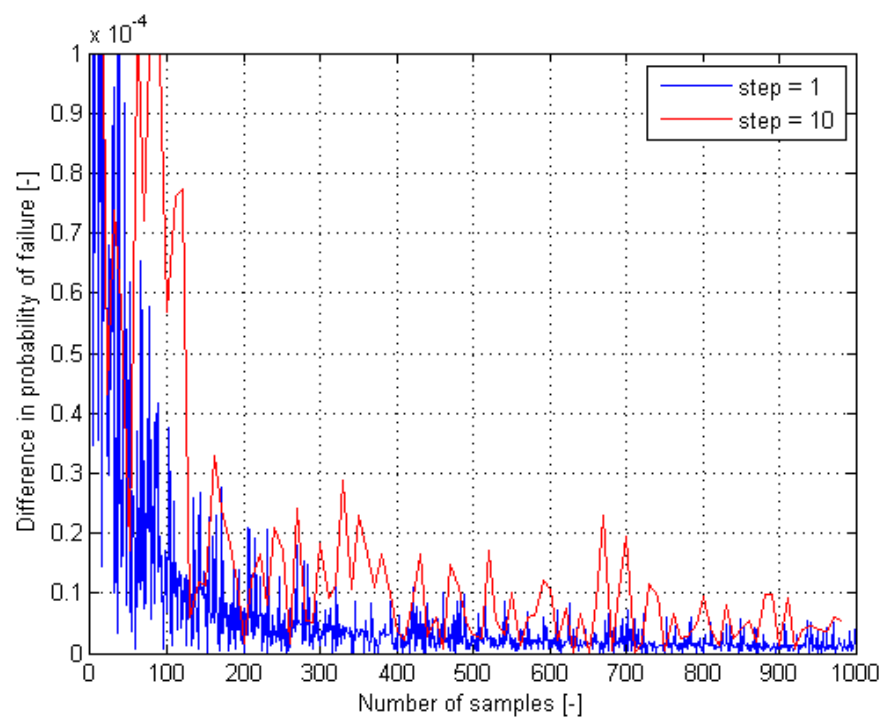

Figure 15 Convergence diagram of probability of failure determined by Monte Carlo routine.

\section{DISCUSSION}

This section discusses the relevance of the results for the Dutch coast and the necessity to collect measurement data on this subject.

\section{Relevance}

This research shows a significant influence of coastal curvatures on the probability of dune failure. The results, however, are presented in normalized figures to make a fair comparison between models possible. The large underestimation of the influence of coastal curvatures by current regulations does not necessarily mean that the actual probability of failure is underestimated. It appeared that only for extremely curved coastal stretches the underestimation exceeds the general overestimation of the DUROS+ model. Only in these rare cases the risk of an actual absolute underestimation exists.

Also the influence of incident wave angles appears to be large. Especially the interaction between incident wave angles and the influence of coastal curvatures needs special attention. Incorporation of the influence of coastal curvatures without incorporating the incident wave angle will most likely result in again a large overestimation of the probabilities of failure.

In context of climate change and the corresponding sea level rise, it is likely that a part of the Dutch dunes need to be strengthened to meet the legal regulations in the near future. This may be prevented if the overestimation in the current regulations is reduced. This reduction only seems acceptable if at least the influence of coastal curvatures is incorporated. Incorporation of the influence of the incident wave angle is then also required, to prevent different overestimations to occur.

\section{Numerical versus physical modeling}

In principle, this research consists of a comparison between three numerical models: DUROS+, DurosTA and XBeach. All three models pretend to be able to describe the influence of coastal curvatures to some extend. The results show a significant influence. However, these results can not be substantiated using measurement data. This is due to a lack of physical model tests and field measurements on this subject. Carrying out physical model tests on scale, seems to be a precarious business since scaling longshore curvatures is difficult. Field measurements, on the contrary, are very well possible. Concerning the likely great importance, the results obtained during this research should be read as an encouragement of performing such measurements. 


\section{CONCLUSIONS}

Based on this research, several conclusions can be drawn. First of all, the increase of the probability of failure due to increasing coastal curvatures can be considerable. For the strongest curved reference case (Table 1) the increase amounts $88 \%$ according to a normative return period of 4,000 years. For a normative return period of 10,000 years, applicable for the coast of Holland, the increase for such coastal curvatures is even $125 \%$. For more moderate curved coastlines the increase is still $20 \%$ to $70 \%$. Even coasts that are considered straight according to current regulations in The Netherlands might suffer from a $15 \%$ larger probability of failure due to coastal curvatures.

The decrease of the probability of failure due to an increasing incident wave angle can also be considerable. This effect is more pronounced along curved coastlines than along straight coastlines. Due to the non-linear relation between the incident wave angle and the erosion volumes, a small incident wave angle already decreases the effect of a coastal curvature considerably. For sufficient large incident wave angles the effect of the coastal curvature can be fully canceled out.

The deterministic or physical relative importance or sensitivity of the DurosTA dune erosion model for all model parameters increases with increasing coastal curvature. Therefore the demands on the data used and the physical modeling increases with increasing coastal curvatures. The increase of the relative importance of the sediment diameter is large with respect to other model parameters. For strongly curved coastlines the DurosTA model becomes more sensitive for the sediment diameter than for the storm surge level. Taking into account the relevance of this sensitivity in practice, by using a semi-probabilistic approach, the sensitivity for the sediment diameter is even more pronounced. These findings are especially relevant for the development of models that incorporate longshore transport gradients.

In a probabilistic sense, the relative importance of the storm surge level increases with increasing coastal curvature at the expense of the other model parameters. For strongly curved coastlines the storm surge level almost solely determines the expected retreat distance corresponding to the most probable failure scenario. This can be explained by the correlation between the storm surge level and the wave parameters, which bundles the importances of these parameters. This correlation should be chosen sound especially for curved coastlines.

Current regulations underestimate the influence of the coastal curvatures considerably with respect to the results obtained from DurosTA. The differences are in the order of magnitude of $10 \%$ to $70 \%$ depending on the coastal curvature and the observed return period. Since the computational methods for curved coastlines prescribed by VTV2006 are empirical and lack a thorough scientific basis, while DurosTA is developed especially for these types of calculations, the physics in and results from the latter model are considered to be more trustworthy.

The hydraulic conditions at Den Helder are only slightly more severe than in Hoek van Holland in terms of resulting retreat distance. The storm surge level decrease in Den Helder with respect to Hoek van Holland is nevertheless more than compensated by the increased wave action. Besides, the difference between the locations increases with increasing coastal curvature. This can be explained by the increased effectiveness of wave action by coastal curvatures.

\section{RECOMMENDATIONS}

Based on the results of this research, it is recommended to consider incorporation of both coastal curvatures and incident wave angles in legal regulations for The Netherlands. However, field measurements and additional computations using a larger variety and more realistic coastal profiles should be performed. Limitations of the DurosTA model (Hoonhout, 2009) can be overcome by using the XBeach model. It is shown that using true $2 \mathrm{DH}$ computations, additional phenomena might become important. Additional research is recommended to investigate these phenomena.

\section{ACKNOWLEDGEMENTS}

This research was carried out as part of a research project to obtain the Master of Science degree of Delft University of Technology. The research was conducted at Deltares at the department Water Safety. The departments Morphology and Sedimentary Systems and the unit Hydraulic Engineering were closely involved. The contributions in time, knowledge and efforts from Deltares are greatly appreciated. 
The department Hydraulic Engineering of Delft University of Technology supplied the necessary funding for additional verifications of the results and the preparation of this paper, which is also kindly appreciated.

Publication and presentation of the paper is funded by the SBW-Dunes project at Deltares and the department Hydraulic Engineering of Delft University of Technology.

\section{REFERENCES}

Dillingh, D. and Visser, C. 1984. Rekenmodel voor extra duinafslag ten gevolge van een gradiënt in het langstransport als gevolg van een kromming van de kustlijn (Computational model for extra dune erosion due to a gradient in the longshore transport due to the curvature of the coastline), Centrum voor Onderzoek Waterkeringen (Centre for Research Water Defences), S-81.040 (in Dutch).

Fisherman, G. S. 1996. Monte Carlo: concepts, algorithms, and applications. Springer.

Hoonhout, B. M. 2009. Dune erosion along curved coastlines. Delft University of Technology, MSc Thesis. http://repository.tudelft.nl/view/ir/uuid:ee47e597-871a-4caf-82d0-96946cd6052b/.

JARKUS. 2008. http://opendap.deltares.nl/thredds/dodsC/opendap/rijkswaterstaat/jarkus/profiles/transect.nc, Internet.

Meeuws, P. 1997. Het ontwerppunt bij Monte Carlo simulatie (Design point with Monte Carlo simulation). Delft University of Technology, MSc Thesis. http://repository.tudelft.nl/view/ir/uuid:c7b4e99f-71be-4903-9ea3-50631715896e/.

Roelvink, J. A., Reniers, A. J. H. M., van Dongeren, A. R., van Thiel de Vries, J. S. M., Lescinski, J. M., and McCall, R. T. 2006. XBeach model description and manual, UNESCO-IHE Institute for Water Education, N62558-06-C-2006.

Steetzel, H. J. 1990. Effect langstransport gradiëenten op mate van duinafslag, berkeningen met het DUROSTA-model (Effect of longshore transport gradients on the amount of dune erosion, computation with the DUROSTAmodel), WL | Delft Hydraulics, H298, part V (in Dutch).

Steetzel, H. J. 1992a. Vergelijking DUROS/DurosTa (Comparison DUROS/DurosTa), WL | Delft Hydraulics, H1201, part II (in Dutch).

Steetzel, H. J. 1992b. Verifcatie DurosTA (Verification DurosTA), WL | Delft Hydraulics, H1201, part I (in Dutch).

Steetzel, H. J. 1993. Cross-shore Transport during Storm Surges, Delft University of Technology, $\mathrm{PhD}$ Thesis. http://repository.tudelft.nl/view/ir/uuid:83f01c82-f290-485e-b078-7643f1c2d419/.

Van Thiel de Vries, J. S. M. 2009. Dune erosion during storm surges, Delft University of Technology, PhD Thesis. http://repository.tudelft.nl/view/ir/uuid:885bf4b3-711e-41d4-98a4-67fc700461ff/.

Vellinga, P. 1983. Duinafslag bij gebogen kusten, orde-grootte bepaling van de gradiënt van het langstransport tijdens duinafslag aan een gebogen kust (Dune erosion at curved beaches, determination of the order of magnitude of the longshore sediment transport gradient under dune erosion conditions), WL | Delft Hydraulics, M1263, part V (in Dutch).

Vellinga, P. 1986. Beach and Dune Erosion during Storm Surges, Delft University of Technology, PhD Thesis. http://repository.tudelft.nl/view/ir/uuid:eb7a4d20-86d2-469a-932a-dec0518274bb/.

VTV2006. 2007. Voorschrift Toetsen op Veiligheid Primaire Waterkeringen (Regulation Safety Assessment Primary Water Defences), Ministerie van Verkeer en Waterstaat (Ministry of Transport, Public Works and Water Management), (in Dutch).

Walstra, D. J. R., Diermanse, F. L. M., van Geer, P. F. C., van Thiel de Vries, J. S. M., and van de Graaff, J. 2008. SBWDuinen2-Ontwikkeltraject, eerste aanzet tot de ontwikkeling van het 2011 Duintoetsinstrumentarium (SBWDuinen2-Developmentroute, first initiative to the development of the 2011 dune assessment instrument), Deltares, H5019.20 (in Dutch).

WL | Delft Hydraulics. 2006. Dune Erosion - Product 2: Largescale model tests and dune erosion prediction method, WL | Delft Hydraulics, H4357.

WL | Delft Hydraulics. 2007. Dune Erosion - Product 3: Probabilistic dune erosion prediction method, WL | Delft Hydraulics, H4357. 